\title{
Effect of Hybrid Layer and Thickness on Stress Distribution of Cervical Wedge-Shaped Restorations
}

\author{
Evrim Eliguzeloglua \\ Oguz Eraslan ${ }^{b}$ \\ Huma Omurluc \\ Gurcan Eskitascıoglu ${ }^{d}$ \\ Sema Bellie
}

\section{ABSTRACT}

Objectives: The aim of this finite elemental stress analysis study was to evaluate the effect of a hybrid layer and the hybrid layer thickness on the shear stress distribution in mandibular premolar teeth under occlusal loading.

Methods: The mandibular premolar tooth was selected based on the anatomical measurements suggested by Wheeler. The analysis was performed with a computer with the SAP 2000 structural analysis program. Three different mathematical models were evaluated; 1) composite restoration without a hybrid layer 2) composite restoration with a $1.5 \mu \mathrm{m}$ thick hybrid layer and 3) composite restoration with a $3 \mu \mathrm{m}$ thick hybrid layer. A total of $200 \mathrm{~N}$ of occlusal loading force was simulated from the buccal tubercule and central fossa of the premolar tooth. The findings were drawn by the Saplot program.

Results: In model B, the output showed that hybrid layer reduced the shear stress concentration especially on gingival margin of the composite. Similarly shear stress intensity was decreased by a thick hybrid layer in model $\mathrm{C}$, especially on the gingival margin of the composite.

Conclusions: The hybrid layer and its thickness plays an important role on stress distribution and intensity in cervical restorations. (Eur J Dent 2010;4:160-165)

Key words: Finite element analysis; Hybrid layer; Premolar tooth; Non-carious cervical lesion; Composite restoration.

a DDS, PhD, Assistant Professor, Department of Operative Dentistry and Endodontics, School of Dentistry, University of Yuzuncuyil, Van, Turkey.

b DDS, PhD, Assistant Professor,Department of Prosthetic Dentistry, School of Dentistry, University of Selcuk, Konya, Turkey.

DDS, PhD, Professor, Department of Operative Dentistry, School of Dentistry, University of Gazi, Ankara, Turkey.

d DDS, PhD, Professor, Department of Prosthetic Dentistry, School of Dentistry, University of Yuzuncuyil, Van, Turkey.
DDS, PhD, Professor, Department of Endodontics, School of Dentistry, University of Selcuk, Konya, Turkey.

- Corresponding author:

Evrim Eliguzeloglu

Gulseren sok:

No: 1/6 Anittepe

Phone: +90 5056878137

Fax: +9031222392 26

E- mail: eeliguzelogludyahoo.com 


\section{INTRODUCTION}

Non-carious cervical lesions are characterized by a loss of hard tissue at the cemento-enamel junction.' These lesions are generally wedgeshaped and were previously termed idiopathic cervical erosion lesions, now referred to by Grippo ${ }^{2}$ as abfractions.

A cervical lesion changes the distribution of stress within a tooth. Grippo suggests that if the lesion were left unrestored, the stress concentration caused by the cervical lesion would facilitate further deterioration of the tooth's structure, and hypothesizes that restoration of the lesion will decrease the concentration of the stress and progression of the lesion. ${ }^{3}$

These lesions were restored with mostly resin-based esthetic restorative materials, such as composite or resin-based glass ionomer. Many failures were seen in the cervical composite restorations, ${ }^{4,5}$ researchers report a greater loss of retention of these restorations among older patients. ${ }^{6,7}$ Lee states that this may occur due to either fewer teeth bearing the occlusal load in older patients, or to the protective mechanisms of natural dentition, such as cuspid guidance wearing down and allowing for greater lateral forces to be transmitted to the teeth. ${ }^{8}$

Elastic composites have been suggested to restore cervical lesions in order to accommodate bending and flexing. ${ }^{6}$ A possible alternative for accommodating the stresses between restorations and dentin is the application of an elastic resin layer (low viscosity composites, filled adhesives) of a sufficient thickness. ${ }^{9-11}$ Van Meerbeek et al ${ }^{12}$ proposed that an adhesive layer and an intermediate layer may have a strain capacity sufficient to relieve stress between the shrinking composite restoration and rigid dentin substrate. Uno and Finger ${ }^{13}$ speculate that the hybrid layer might play a role in absorbing stress in the dentin bonding procedure.

In complicated structures, it is difficult to achieve an accurate analytical solution. Numeric methods, such as the finite element method of analysis, can be considered a practical approach. Finite element analysis divides the problem domains into a collection of smaller parts (elements) and an overall approximated solution to the original problem is determined. In this method, solutions for each element are combined in order to obtain a solution for the entire problem. ${ }^{14}$
The aim of this particular finite element stress analysis (FEM) study is to evaluate the effect of a hybrid layer and its thickness on the distribution and intensity of shear stress formed under occlusal loading in a premolar tooth which had a wedge shaped cervical lesion restored with composite. The null hypothesis of this FEM study was that the hybrid layer and its thickness would alter the shear stress concentration in wedge-shaped cervical lesions restored with a resin composite.

\section{MATERIALS AND METHODS}

In this study, a three-dimensional finite element model simulating the cross-section of a first mandibular premolar tooth was used; the mathematical model was based on the anatomical measurements suggested by Wheeler. ${ }^{15}$ The model included simulations of cortical bone, spongy bone, periodontal membrane, enamel, dentin, composite, adhesive layer, hybrid layer, and pulp tissue. In this model, the cortical bone level was formed through to the root, according to a natural tooth. All materials were homogenous, isotropic, and linearly elastic; the elastic properties of these tissues and materials were determined from the literature (Table 1). The thickness of the composite restorations was $2 \mathrm{~mm}$ and the width of the adhesive layer was $30 \mu \mathrm{m}$. The width of the hybrid layer was defined as $1.5 \mu \mathrm{m}$ in model 2 , and $3 \mu \mathrm{m}$ in model 3. ${ }^{16}$ Each mathematical model was composed of 966 nodes and 726 solid elements. The analysis was performed using a computer (Sony Vaio UGN-FZ320EIB $1.66 \mathrm{GHz}$ Intel Core 2 Duol and an SAP 2000 structural program (Computer Structures Inc. Berkley, CA).

Three different restoration models were evaluated:

Model A: Wedge-shaped non-carious cervical lesion, restored with a composite resin and without a hybrid layer.

Model B: Wedge-shaped non-carious cervical lesion, restored with a composite resin and a hybrid layer measuring $1.5 \mu \mathrm{m}$ thick. ${ }^{16}$

Model C: Wedge-shaped non-carious cervical lesion, restored with a composite resin and a hybrid layer measuring $3 \mu \mathrm{m}$ thick. ${ }^{16}$

All models were loaded from the central fossa and buccal tubercule vertically to the tooth axis with a total of $200 \mathrm{~N}$ of loading force (divided into $100 \mathrm{~N}$ per point) (Figure 1).1,15 The final elements on the $X$ and $Y$ axis for each model were assumed 
to be fixed for boundary conditions. Shear stress distribution and amounts were calculated using Von Misses stress criteria. ${ }^{17}$ The outputs were transferred to the SAPLOT program, which displayed the resulting shear stress.

\section{RESULTS}

Model A showed the lower premolar tooth model with a wedge-shaped non-carious cervical lesion restored with composite resin (Figure 2);

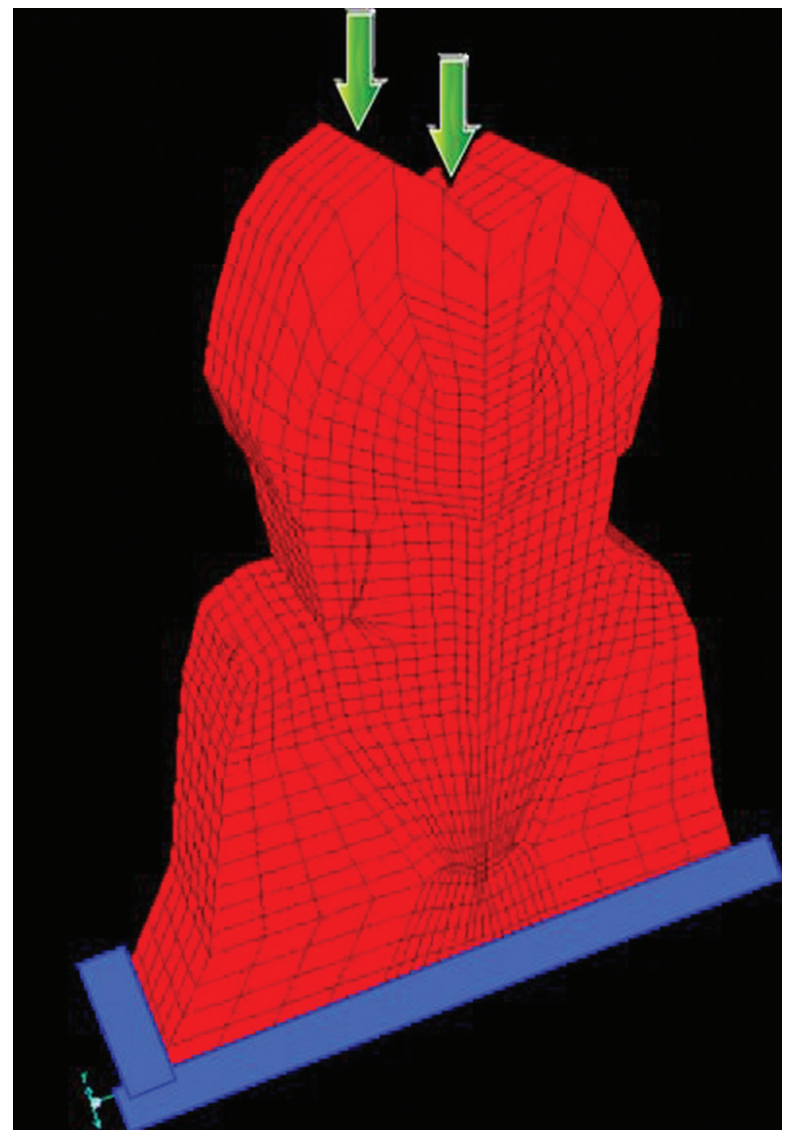

Figure 1. The lower premolar tooth model that was loaded with $200 \mathrm{~N}$ from the buccal tubercule and central fossa is shown with green. Boundary conditions are indicated with blue. the model did not include an adhesive and hybrid layer. When a $200 \mathrm{~N}$ load was applied to the buccal tubercule and central fossa ( $100 \mathrm{~N}$ each), additional shear stress concentration was observed on the gingival margin of the composite restoration (dark blue; 46.2-50.0 MPal. Composite restoration was illustrated mesio-distally in Figure 2a. The shear stress values seemed to decrease in the occlusal area, especially when compared to the gingival area in this illustration llight yellow; 23.1-26.9 MPa). Bucco-lingual composite restoration was illustrated in Figure 2b, and the shear stress intensity seemed to decrease gingivally towards the lingual area.

Model B showed the shear stress distribution in a lower premolar tooth model with a wedgeshaped non-carious cervical lesion restored with composite resin (Figure 3). A 1,5 $\mu \mathrm{m}$ thick hybrid layer was added to the model (Figure 3c); although the shear stress distribution appeared to be similar to that of Model A, a decrease in shear stress intensity was observed in model $B$ in all composite surfaces (gingival, axial, occlusal). Composite restoration was illustrated mesio-distally in Figure $3 a$, and bucco-lingually in Figure 3b. According to these illustrations the gingival margin of the composite was the most intense surface (light blue; 42.3-46.2 MPal.

When a $3.0 \mu \mathrm{m}$ thick hybrid layer was included in Model C (Figure 4c), shear stress distribution at the gingival, occlusal and cervical margins of the restoration decreased (Figures $4 a, b$ ). This decrease was observed, at the gingival margin of the restoration especially when compared to Model $A$ (the lightest blue; 38.5-42.3 MPa).

Table 1. Elastic properties, Young modulus (E) and Poissons ratio $(\mu)$ of the structures used in the FEM models.

\begin{tabular}{lccc}
\hline Material & Young's modulus (GPa) & Poisson's ratio (V) & References \\
\hline Enamel & 84 & 0.33 & Wheeler $^{15}$ \\
Dentin & 17.5 & 0.31 & Menicucci G $^{35}$ \\
Pulp & 0.0021 & 0.45 & Mac Gregor $^{36}$ \\
Periodontal membrane & 0.069 & 0.45 & Reinhardt RA $^{37}$ \\
Cortical bone & 13.7 & 0.30 & Holmes DC $^{22}$ \\
Spongiose bone & 1.37 & 0.30 & Holmes DC $^{22}$ \\
Composite & 16.4 & 0.28 & Belli S3 $^{30}$ \\
Adhesive layer & 10.5 & 0.28 & Belli S3 $^{30}$ \\
Hybrid layer & 15.5 & 0.28 & Belli S $^{30}$ \\
\hline
\end{tabular}




\section{DISCUSSION}

Developing hybridization with acidic solutions and bonding systems is the most important mechanism of bonding to tooth structures. The hybrid layer is created by the practitioner, and its thickness can be altered by using various procedures (i.e, prolonging acid etching time, additional phosphoric acid usage before self-etch primer) and adhesive systems (total-etch, self-etch). ${ }^{16,18-20}$ The chemical and physical features of a hybrid layer are quite different from the normal tooth structure, because it has been partially demineralized then infiltrated with resin. ${ }^{21}$ Van Meerbeek et $\mathrm{al}^{12}$ evaluated the hardness and elasticity of the resindentin bonding area and reports that the elastic structure of a hybrid layer formed by collagen tissue and resin can tolerate the stress of the resindentin bonding area.

During normal functional and parafunctional movements, the teeth are exposed to acute occlusal stress which is distributed throughout the entire tooth. ${ }^{1}$ Many stress analysis methods are being used to determine this stresses within the

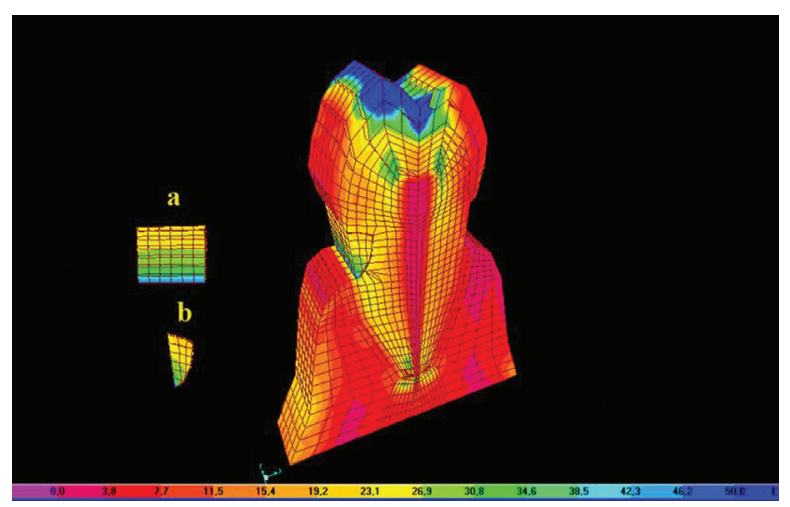

Figure 2. Wedge-shaped noncarious cervical lesion was restored with composite resin without a hybrid layer. a) Mesiodistal composite restoration is seen. b) Bucco-lingual composite restoration is seen.

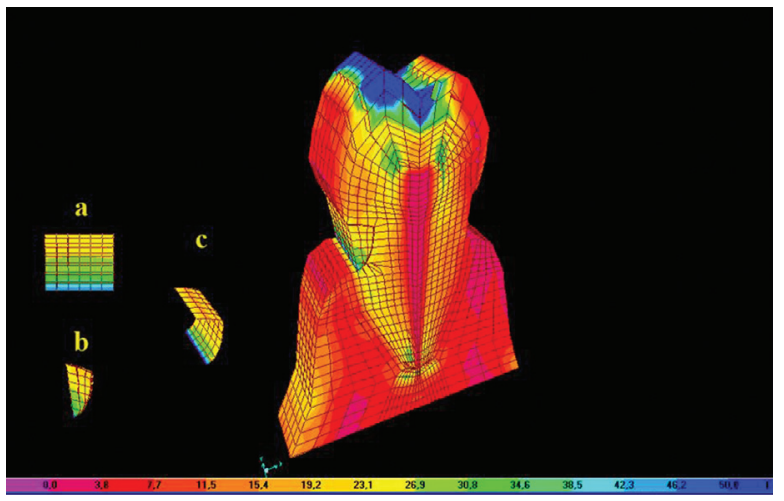

Figure 3. Wedge-shaped noncarious cervical lesion was restored with composite resin with a thin hybrid layer. al Mesiodistal composite restoration is seen. b) Bucco-lingual composite restoration is seen. c) Thin hybrid layer $(1.5 \mu \mathrm{m})$. tooth; among these methods FEM is most advantageous because of improvements in computer technology. ${ }^{14,22}$ In addition, the load direction and amount can be ideally applied, and stress type and localization within the tooth can be clearly determined using this method. ${ }^{23}$ It is because of these advantages, that the FEM was used in the present study.

Various studies have used FEM to determine the stress concentration in the cervical area due to occlusal forces; ${ }^{24-27}$ the majority of these studies generally aim to understand the etiology of noncarious cervical lesions. ${ }^{24-26}$ The results of previous studies suggest that, all occlusal forces cause stress concentration in the cervical area; however, not enough knowledge exists about the effect of the stress concentration in cervical restorations. Grippo $^{3}$ reports that stress concentration in the cervical area does not only cause cervical lesions, but is also an important factor that adversely affects restoration bonding in this area.

In the present study, FEM was used on lower premolar tooth because studies on the frequency of non-carious cervical lesions indicate that lower premolar teeth are the most affected tooth group. ${ }^{28}$ Holmreng et al $^{29}$ reports that, the stress concentration in the cervical area of premolar teeth is greater than that of other tooth groups because of the differences in crown and root morphology. To simulate centric occlusion, in the current study, a total of $200 \mathrm{~N}$ were applied vertically on the buccal tubercule and central fossa of the premolar tooth models. Centric occlusion can be standardized to chewing functions generated by complex movements and is the location with the lowest controversy in force localization, amount,

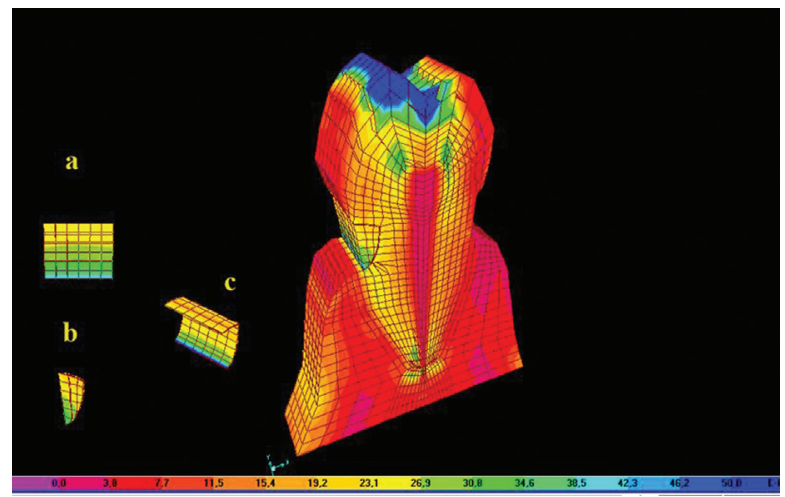

Figure 4. Wedge-shaped noncarious cervical lesion was restored with composite resin with a thick hybrid layer. a) Mesiodistal composite restoration is seen. b) Bucco-lingual composite restoration is seen. c) Thick hybrid layer $(3 \mu \mathrm{m})$.

\section{April 2010 - Vol.4}


and direction. For this reason, centric occlusion was taken as a standard, and occlusal forces were applied on the tooth model.

When a force is applied on the occlusal surface of restored teeth, the stress is not only distributed in structures such as enamel and dentin, it is also concentrated in areas such as composite and adhesive layers. ${ }^{30}$ To ensure successful restorative procedure, the bonded interface area must be capable of withstanding occlusal stresses. Belli et $\mathrm{al}^{30}$ analyzed the effects of a hybrid layer on the amount and distribution of stress generated by occlusal forces in premolar teeth restored with a composite and ceramic inlay, and concludes that the hybrid layer reduces stress distribution. Rees et $\mathrm{al}^{31}$ suggests that forming a thick hybrid layer for Class $V$ restorations is necessary to prevent stress from forming in the bonding layer after polymerization shrinkage. Previous FEM studies report that the hybrid layer serves as a cushion to both polymerization shrinkage stress and the stress generated by occlusal forces in Class II cavities. ${ }^{31-33}$ In the current study, we want to determine the effect of the hybrid layer and its thickness on stress intensity of cervical restorations. To do this, we used the same adhesive and composite in all models, but with different hybrid layer thicknesses. When the models were compared, the presence of a hybrid layer altered the shear stress distribution; by adding this layer, the amount of shear stress decreased in all layers of the composite restoration. Although we can conclude that a hybrid layer absorbs stress, our results, further suggest that another adhesive system or composite with different elastic property will effect stress distribution in the cervical region differently.

Unlike previous studies, the current study was conducted on cervical lesions and determined that the degree of shear stress due to occlusal forces was compensated by the hybrid layer in cervical composite restoration. In addition, the current study also evaluated the effect of the hybrid layer thickness on shear stress distribution; by increasing the thickness, shear stress distribution was reduced, especially in the gingival margin of the composite, which may avoid the cervical defects of the restoration, such as fractures or cracks. These results support the null hypothesis: based on these findings, it is suggested that the hybrid layer serves to provide both bonding to tooth structures and a cushion for absorbing shear stresses in cervical restorations.

Studies indicate that clinical success was considerably low in cervical areas when compared to restorations in other areas. ${ }^{1,2,6}$ In addition to sclerotic layers that do not allow for sufficient bonding resistance and formation of hybrid layer in cervical lesions, the negative effects of occlusal forces in this area should not be ignored. ${ }^{4,5,34}$ However, a previous study examined the effects of changing the hybrid layer thickness, in non-carious cervical lesions with different adhesive systems. ${ }^{16}$ In this study, hybrid layer thickness was increased when surface dentin was removed with a bur before the adhesive systems. Within the limitations of the current study, it is concluded that, techniques allowing for a thick and flexible hybrid layer are beneficial in increasing the success rate of cervical area restorations. Further long-term clinical studies must be performed, and the effects of various hybrid layers and adhesives on restoration success must be investigated.

\section{CONCLUSIONS}

The hybrid layer reduces the intensity of shear stress formed under occlusal loading in premolar teeth that have a wedge-shaped cervical lesion restored with composite resin. Furthermore, hybrid layer thickness affects the intensity and distribution of the shear stresses in cervical composite restorations.

\section{REFERENCES}

1. Rees JS, Jagger DC. Abfraction lesions: myth or reality? $J$ Esthet Restor Dent 2003;15:263-271.

2. Grippo JO. Abfractions: a new classification of hard tissue lesions of teeth. $J$ Esthet Dent 1991;3:14-19

3. Grippo JO, Simring M, Schreıner S. Attrition, abrasion, corrosion and abfraction revisited. JADA 2004;135:1109-1118.

4. Van Meerbeek B, Perdigao J, Lambrechts P, Vanherle G. The clinical performance of adhesives. J Dent 1998;26:120.

5. Peumans M, Kanumilli P, De Munck J, Van Landuyt K, Lambrechts P, Van Meerbeek M. Clinical effectiveness of contemporary adhesives: A systematic review of current clinical trials. Dent Mater 2005;21:864-881.

6. Heymann HO, Sturdevant JR, Bayne SC, Wilder AD, Sluder TB, Brunson WD. Examining tooth flexural effects on cervical restorations: a two year clinical study. JADA $1991 ; 122: 41-47$ 
7. Bayne SC, Heymann HO, Sturdevant JR, Wilder AD, Sluder TB. Contributing co-variables in clinical trials. Am J Dent 1991;4:247-250.

8. Lee WC, Eakle WS. Stress-induced cervical lesions: review of advances in the past 10 years. $J$ Prosthet Dent 1996;75:487-494.

9. Unterbrink GL, Liebenberg WH. Flowable resin composites as 'filled adhesives': literature review and clinical recommendations. Quintessence Int 1999;30:249-257.

10. Montes MAJR, Goes MF, Cunha MRB, Soares AB. A morphological and tensile bond strength evaluation of an unfilled adhesive with low viscosity composites and a filled adhesive in one and two coats. J Dent 2001;29:435-441.

11. Labella R, Lambrechts $P$, Van Meerbeek B, Vanherle G. Poymerization shrinkage and elasticity of flowable composites and filled adhesives. Dent Mater 1999;15:128-137.

12. Van Meerbeek B, Williems G, Celis JP, Roos JR, Braem M, Lambrechts P, Vanherle G. Assessment by nano-indentation of the hardness and elasticity of the resin dentin bonding area. J Dent Res 1993;72:1434-1442.

13. Uno S, Finger WJ. Function of the hybrid zone as a stressabsorbing layer in resin-dentin bonding. Quintessence Int 1995;26:733-738.

14. Geramy A, Sharafoddin F. Abfraction: 3D analysis by means of the finite element method. Quintessence Int 2003;34:526533.

15. Wheeler RC. Wheeler's dental anatomy, physiology and occlusion. Saunders Company, London, 1974;405-486.

16. Eligüzeloglu E, Omurlu H, Eskitascioglu G, Belli S. Effect of surface treatments and different adhesives on the hybrid layer thickness of non-carious cervical lesions. Oper Dent 2008;33:338-345.

17. Papavassiliou G, Kamposiora P, Bayne SC, Felton DA. 3D FEA of osseointegration percentages and patterns on implant bone interfacial stress. J Dent 1997;25:485-491.

18. Radovic I, Vulicevic ZR, Garcia-Godoy F. Morphological evaluation of 2- and 1- step self etching system interface with dentin. Oper Dent 2006;31:710-718.

19. Harnirattisai C, Inokoshi S, Shimada Y, Hosoda H. Adhesive interface between resin and etched dentin of cervical erosion/abrasion lesions. Oper Dent 1993;18:138-143.

20. Arrais CA, Giannini M. Morphology and thickness of the diffusion of resin through demineralized or unconditioned dentinal matrix. Pesqui Odontol Bras 2002;16:115-120.

21. Nakabayashi N, Kojima K, Masuhara E. The promotion of adhesion by the infiltration of monomers into tooth substrates. J Biomed Mater Res 1982;16:265-273.

22. Holmes DC, Loftus JT. Influence of bone quality on stress distribution for endosseous implants. J Oral Implantol 1997:23:104-111.
23. Keyak JH, Fourkas MG, Meagher JM, Skinner HB. Validation of an automated method of three-dimensional finite element modelling of bone. J Biomed Eng 1993;15:505-509.

24. Rees JS. The effect of variation in occlusal loading on the development of abfraction lesions: a finite element study. $J$ Oral Rehabil 2002;29:188-193.

25. Rees JS, Hammadeh M, Jagger DC. Abfraction lesion formation in maxillary incisors, canines and premolars: a finite element study. Eur J Oral Sci 2003;111:149-154.

26. Palamara D, Palamara JE, Tyas MJ, Messer HH. Strain patterns in cervical enamel of teeth subjected to occlusal loading. Dent Mater 2000;16:412-419.

27. Kuroe $T$, Itoh $H$, Caputo AA, Konuma M. Biomechanics of cervical tooth structure lesions and their restoration. Quintessence Int 2000;31:267-274.

28. Borcic J, Anic I, Urek MM, Ferreri S. The prevalence of noncarious cervical lesions in permanent dentition. J Oral Rehabil 2004;31:117-123.

29. Holmreng EP, Seckinger RJ, Kilgren LM, Mante F. Evaluating parameters of osseointegrated dental implants using finite element analysis--a two-dimensional comparative study examining the effects of implant diameter, implant shape, and load direction. J Oral Implantol 1998;24:80-88.

30. Belli S, Eskitascıoglu G, Eraslan O, Senawongse P, Tagami J. Effect of hybrid layer on stress distribution in a premolar tooth restored with composite or ceramic inlay: an FEM study. J Biomed Mater Res B Appl Biomater 2005;74:665-668.

31. Rees JS, O'dougherty D, Pullin R. The stress reducing capacity of unfilled resin in a Class V cavity. J Oral Rehabil 1999;26:422-427.

32. Ausiello P, Apicella A, Davidson CL, Rengo S. 3D-finite element analyses of cusp movements in a human upper premolar, restored with adhesive resin-based composites. $J$ Biomech 2001;34:1269-1277.

33. Ausiello P, Apicella A, Davidson C. Effect of adhesive layer properties on stress distribution in composite restorations-a 3D finite element analysis. Dent Mater 2002;18:295-303.

34. Tay FR, Pashley DH. Resin bonding to cervical sclerotic dentin: A review. J Dent 2004;32:173-196.

35. Menicucci G, Mossolov A, Mozzati M, Lorenzetti M, Preti G. Tooth-implant connection: some biomechanical aspects based on finite element analyses. Clin Oral Implants Res 2002;13:334-341.

36. Mac Gregor AR, Miller TP, Farah JW. Stress analysis of mandibular partial dentures with bounded and free-end saddles. J Dent 1980;8:27-34.

37. Reinhardt RA, Pao YC, Krejici RF. Periodontal ligament stresses in the initiation of occlusal traumatism. $J$ Periodontal Res 1984;19:238-246. 